\title{
Gastroenteritis Outbreak Among Mountaineers Climbing the West Buttress Route of Denali-Denali National Park, Alaska, June 2002
}

\author{
Joseph B. McLaughlin, MD, MPH; Bradford D. Gessner, MD, MPH; Ann Marie Bailey, RN, MS
}

From the Epidemic Intelligence Service assigned to the Alaska Department of Health and Social Services, Epidemiology Program Office, Centers for Disease Control and Prevention, Atlanta, GA (Dr McLaughlin); and the Division of Public Health, Alaska Department of Health and Social Services, Anchorage, AK (Dr Gessner and Ms Bailey).

\begin{abstract}
Objective.-To determine the burden of and risk factors for diarrheal illness among mountaineers climbing Denali during the spring of 2002.

Methods.-We conducted a retrospective cohort study of all willing and available climbers who returned to base camp from June 11 to 14,2002 . We used a questionnaire that addressed illness status, demographics, and potential risk factors for illness. A case of diarrhea was defined as self-reported diarrhea (loose stool) in a Denali climber who did not have diarrhea before arrival at base camp.

Results. - Thirty-eight (29\%) of the 132 climbers who were interviewed reported experiencing diarrhea at some point on the mountain. Spending 8 or more days at the 17200 -foot high camp; being a member of a climbing party in which at least 1 other person also had diarrhea, especially if tent occupancy was 3 or more; and not receiving education about disease risk-reduction techniques among climbers who were on a guided expedition were associated with increased risk of illness.

Conclusions.- - To prevent infectious diarrheal outbreaks among mountaineers climbing Denali (and other highly trafficked alpine routes), we recommend that park staff provide climbers with detailed information related to minimizing disease risk and develop more effective strategies for preventing climbers from depositing fecal material directly into snow along the route, such as establishing and enforcing firmer penalties for noncompliance with existing human waste disposal regulations and requiring the use of personal stool-hauling devices.
\end{abstract}

Key words: alpine, diarrhea, hygiene, prevention

\section{Introduction}

On May 21, 2002, the Alaska Section of Epidemiology was notified by a Denali National Park climbing ranger that 4 mountaineers who were ascending the West Buttress route of Denali (Mount McKinley) developed diarrheal illness while on the mountain. The 4 climbers complained of acute onset of loose stools, abdominal cramps, and general malaise. On May 23, a fifth climber complained of acute onset of 6 bouts of vomiting and numerous loose stools. He was evaluated in the medical tent at the 14 200-foot high camp, required intravenous hydration for 2 days, and was subsequently sent down

Corresponding author: Joseph McLaughlin, MD, MPH, Division of Public Health, Alaska Department of Health and Social Services, 3601 C St, Suite 540, Anchorage, AK 99503 (e-mail: joe_mclaughlin@ health.state.ak.us). to base camp. On June 10, 2002, Section of Epidemiology staff traveled to the Denali 7200-foot high base camp to determine the burden of and risk factors for diarrheal illness among climbers.

Located in Denali National Park, Alaska, Denali is the tallest mountain in North America (elevation 20320 feet), and the West Buttress route of Denali is one of the most highly frequented alpine climbing routes in the US park system. Roughly 1000 climbers ascend the popular West Buttress route every year, each spending an average of 2 to 3 weeks on the mountain.

Two designated campsites with established pit latrines are along the route, located at 7200 and 14200 feet of altitude. Numerous intermediate campsites along the route do not have pit latrines. Existing regulations require that climbers use latrines, crevasse their fecal waste, or carry their fecal waste off the mountain. Most 
climbers begin their ascent of Denali from the 7200-foot high base camp, which is equipped with an emergency medical tent and a glacial landing strip for airplanes. The 14 200-foot high camp also has an emergency medical tent. Because of the deadly risk of falling into crevasses, as well as extreme cold, blizzard conditions, and fatigue, particularly at the higher elevations, climbers often decide to defecate in the snow while traveling in or near their camp in order to prevent the hassle of using established pit latrines or disposing fecal waste in crevasses. Personal hygiene after defecating includes the use of toilet paper, snow, or rocks. High winds spread fecal particles onto the top layers of snow, which is the water source for climbers.

\section{Methods}

\section{RETROSPECTIVE COHORT STUDY}

To determine risk factors for illness, we conducted a retrospective cohort study of all willing and available climbers who returned to base camp from June 11 to 14 , 2002. We used a self-administered questionnaire that addressed illness status, demographics, and potential risk factors for illness. A case of diarrhea was defined as selfreported diarrhea (loose stool) in a Denali climber who did not have diarrhea before arrival at base camp.

\section{STATISTICAL METHODS}

Risk ratios and their Taylor series 95\% CIs were calculated by EpiInfo 2000 version 1.1 .2 statistical software. ${ }^{1}$ Multiple logistic regression analyses were calculated by SPSS version 11.0.1 statistical software (SPSS Inc, Chicago, IL). Variables with $P>.05$ were removed from the model.

\section{Results}

\section{CHARACTERISTICS OF STUDY SUBJECTS}

We received a total of 132 questionnaires from 185 Denali climbers who returned to base camp from June 11 to 14,2002 . The majority of responding climbers were men $(n=119,90 \%)$. The median age of climbers was 34 years (range 18-72). Climbers came from 20 different countries, and the median climbing party size was 4 persons (range 1-12). The mean number of persons per tent was 2 . Forty-two (32\%) were on a commercially guided trip.

Climbers spent a mean of 18 days (range 7-28) on the mountain. The West Buttress route was used by 126 $(96 \%)$ of the climbers. Fifty-one $(39 \%)$ of the climbers stated that they saw snow contaminated with feces in or near at least 1 of their camps while on the mountain; 35 $(69 \%)$ of these climbers saw feces in the snow at the 17200 -foot high camp, $3(6 \%)$ at a 16000 -foot high camp, $10(20 \%)$ at a 14200 -foot high camp, $1(2 \%)$ at a 12 000-foot high camp, $14(27 \%)$ at an 11000 -foot high camp, $7(14 \%)$ at a 9000-foot high camp, and 4 $(8 \%)$ at base camp.

While on the mountain, climbers reported collecting snow for consumption at least once in the following areas: $32(24 \%)$ collected directly in camp, $103(78 \%)$ collected within $10 \mathrm{~m}$ from camp, and $29(22 \%)$ collected farther than $10 \mathrm{~m}$ from camp. Fourteen (11\%) of the climbers admitted to defecating directly into the snow instead of using a latrine, waste disposal bag, or a plastic stool-hauling container. Twenty-one (16\%) of the climbers performed anal cleansing with snow or rocks after defecation instead of using toilet paper. Fifty-two (41\%) of the climbers reported always washing their hands with a disinfectant (nonspecific) after defecation, $19(14 \%)$ reported usually washing, 13 (10\%) reported sometimes washing, 13 (10\%) reported rarely washing, and $30(23 \%)$ reported never washing. Twenty-one $(16 \%)$ of the climbers said that they always boiled or purified their water before consumption, $10(8 \%)$ said they usually did, 23 (17\%) said they sometimes did, 39 $(40 \%)$ said they rarely did, and 35 (27\%) said they never did.

\section{CHARACTERISTICS OF CASE PATIENTS AND DISEASE BURDEN}

Of the 38 (29\%) climbers interviewed who reported experiencing diarrhea at some point on the mountain, 4 (3\%) reported onset of diarrhea before they arrived on the mountain. These 4 were excluded from all further analysis; therefore, the cumulative incidence of diarrhea among climbers on the mountain in this cohort was $27 \%$. The mean number of episodes of loose stools was 3 per day (range 1-5), and diarrhea lasted a mean of 2 days (range 1-5). In addition to diarrhea, symptoms experienced by case patients included gas $(n=19,56 \%)$, abdominal cramping $(n=10,29 \%)$, vomiting $(n=2,6 \%)$, and mucusy stool $(n=1,3 \%)$. Two $(6 \%)$ of the case patients reported seeking evaluation from a health care provider on the mountain. Symptoms started after a median of 11 days (range 1-21) on the mountain, and 13 (41\%) patients stated that symptoms began during or after their stay at the 17 200-foot high camp. Seven (50\%) of the 14 climbers who reported defecating directly into the snow were ill.

\section{RISK FACTOR ANALYSIS}

Significant risk factors for illness on bivariate analysis included spending 8 or more days at the 17200 -foot 
Risk factors for diarrheal illness among Denali mountaineers-Denali National Park, June 2002*

\begin{tabular}{|c|c|c|c|c|}
\hline \multirow[b]{2}{*}{ Risk factor } & \multicolumn{2}{|c|}{ No. } & \multirow{2}{*}{$\begin{array}{l}\text { Risk } \\
\text { ratio }\end{array}$} & \multirow[b]{2}{*}{$95 \% C I$} \\
\hline & $I l l$ & Well & & \\
\hline Female & 3 & 10 & 1.0 & Ref \\
\hline Male & 31 & 88 & 1.1 & $0.40-3.19$ \\
\hline \multicolumn{5}{|l|}{ Ascended via the West Buttress route } \\
\hline No & 1 & 3 & 1.0 & Ref \\
\hline Yes & 33 & 93 & 1.1 & $0.19-5.87$ \\
\hline \multicolumn{5}{|l|}{ No. of days at the 17200 -foot high camp } \\
\hline $0-3$ & 17 & 61 & 1.0 & Ref \\
\hline $4-7$ & 10 & 29 & 1.2 & $0.60-2.32$ \\
\hline$\geq 8$ & 7 & 3 & 3.2 & $1.79-5.76$ \\
\hline \multicolumn{5}{|c|}{ Always purified or boiled water before consumption } \\
\hline No & 27 & 80 & 1.0 & Ref \\
\hline Yes & 7 & 14 & 1.3 & $0.66-2.63$ \\
\hline \multicolumn{5}{|l|}{ Usually got snow for consumption within the camp } \\
\hline No & 26 & 70 & 1.0 & Ref \\
\hline Yes & 8 & 24 & 0.9 & $0.47-1.83$ \\
\hline \multicolumn{5}{|c|}{ Other group members had diarrhea before arrival on the mountain } \\
\hline No & 32 & 84 & 1.0 & Ref \\
\hline Yes & 1 & 3 & 0.8 & $0.14-4.47$ \\
\hline \multicolumn{5}{|l|}{ Other group members had diarrhea } \\
\hline No & 13 & 56 & 1.0 & Ref \\
\hline Yes & 19 & 27 & 2.2 & $1.20-3.99$ \\
\hline \multicolumn{5}{|c|}{ Other group members had diarrhea (persons who slept in a tent with $\leq 2$ persons) } \\
\hline No & 11 & 40 & 1.0 & Ref \\
\hline Yes & 8 & 14 & 1.7 & $0.79-3.61$ \\
\hline \multicolumn{5}{|c|}{ Other group members had diarrhea (persons who slept in a tent with $\geq 3$ persons) } \\
\hline No & 2 & 14 & 1.0 & Ref \\
\hline Yes & 11 & 10 & 4.2 & $1.08-16.31$ \\
\hline \multicolumn{5}{|c|}{ Usually or always washed hands with a disinfectant after defecating } \\
\hline No & 16 & 40 & 1.0 & Ref \\
\hline Yes & 18 & 53 & 0.89 & $0.50-1.58$ \\
\hline \multicolumn{5}{|c|}{ Received information regarding minimizing disease risk (persons on a guided trip) } \\
\hline No & 7 & 3 & 1.0 & Ref \\
\hline Yes & 5 & 15 & 0.40 & $0.16-0.95$ \\
\hline
\end{tabular}

*Ref indicates referent.

high camp; being a member of a climbing party in which at least 1 other person also had diarrhea, especially if tent occupancy was 3 or more; and not receiving education about disease risk-reduction techniques among climbers who were on a guided expedition (Table). Because tent occupancy and not receiving education were risk factors for subgroups of the study, they were not included in the final multiple logistic regression equation. Two of the 3 independent variables in our final multiple logistic regression model were significant independent risk factors for illness: spending 8 or more days at the 17200 -foot high camp (adjusted odds ratio 41.9, 95\% CI 4.0-442.3) and being a member of a climbing party in which at least 1 other person also had diarrhea (adjusted odds ratio 4.1, 95\% CI 1.6-10.8). Total number of days spent on the mountain was not a significant predictor for illness in bivariate or multivariate analysis. 


\section{Discussion}

Over $25 \%$ of Denali climbers who returned to base camp from June 11 to 14 reported experiencing diarrhea that began after they arrived on the mountain. Diarrhea is commonly documented among mountaineers, ${ }^{2-5}$ and several features of this investigation point toward an infectious etiology. First, climbing with someone with diarrhea increased illness risk. Second, climbers most frequently reported seeing feces around the tent sites at the 17 200-foot high camp, and increased time at this camp was associated with an increased risk of illness. Third, education on good hygienic techniques was protective. Finally, other etiologies seem unlikely; in particular, symptoms associated with altitude sickness do not include diarrhea. ${ }^{6-8}$

Infections in combination with high altitude and cold temperatures put mountaineers at increased risk for acute mountain sickness, hypothermia, and accidents stemming from profound fatigue - all of which can lead to severe consequences. ${ }^{2-4,9-11}$ Correspondingly, health officials, park rangers, and mountaineers need to work together toward optimizing sanitary conditions along highly trafficked alpine routes in the United States and elsewhere. In addition, the potential role of self-prophylaxis with antidiarrheal agents for persons climbing remote alpine routes may be warranted. ${ }^{4}$

Despite existing regulations forbidding fecal deposits directly into snow along the West Buttress route, our results show that numerous climbers saw fecal deposits in or near campsites along the route, with most sightings at the 17200 -foot high camp. In addition, 7 climbers who were ill admitted to defecating directly into the snow along the route. Accordingly, to provide a more sanitary environment on Denali, US National Park Service staff are working to make personal stool-hauling devices a legal requirement for future climbers, primarily at the higher elevations where climbers are faced with a very extreme environment, thereby making the task of depositing waste into a crevasse more onerous (eg, at the 17 200-foot high camp, the nearest crevasse suitable for fecal depositing is $100 \mathrm{~m}$ from camp, and climbers need the protection of a rope to approach the crevasse). In 2002, 200 of the 1093 persons who attempted to climb Denali via the West Buttress route volunteered to use Clean Mountain Cans above the 14 200-foot high camp. ${ }^{12}$

Similar work is also being conducted in other highly trafficked alpine areas. For example, the ministry of tourism in Nepal regulates human waste at the Base Camp of Mount Everest, requiring climbing teams to pay for permits for a latrine or disposal system, and all waste has to be portered out. ${ }^{13}$ In addition, permits are required to climb numerous other popular mountains in Nepal. Permitted climbers are required to be accompanied by a guide, whose duty, in part, is to ensure proper disposal of waste materials. ${ }^{14}$ On Mount Rainier, toilet facilities are available at several designated camps, and climbers are advised to use Blue Bags for hauling feces off the mountain in areas were toilets are not available. ${ }^{15}$

The limitations of this study include the fact that for the purposes of increasing sensitivity of the study, we decided to include all climbers with self-reported diarrhea, regardless of the number of episodes of loose stool they had in a 24-hour period. Also, we selected study subjects from a brief period during the overall 3-month climbing season on Denali, and thus our results may not be representative of the entire cohort of climbers on Denali during the study year. Finally, collection of stool samples was attempted but proved to be logistically impractical, primarily because of the lack of privacy and sanitary conditions at base camp. In addition, climbers were usually in a hurry to catch the next available air taxi off the mountain and often did not have the time required for specimen collection.

As growing numbers of persons climb popular alpine routes on Denali, Mount Rainier, Mount Everest, and other mountains, it is likely that communicable disease outbreaks (with their potentially serious sequelae at high altitudes) will become increasingly more common. Therefore, on the basis of the results of this investigation, we recommend that all mountaineers who climb highly trafficked alpine routes should be provided with detailed information on appropriate hygiene and illnessprevention strategies (eg, washing hands with alcoholbased hand sanitizers containing $60 \%-95 \%$ alcohol or antiseptic soaps and detergents after every bowel movement and before cooking and eating, ${ }^{16}$ using water purification [eg, iodine] tablets in all water that is used for consumption, and avoiding crowded sleeping arrangements in tents). We also recommend that park officials continue to work toward enhancing sanitation on Denali by establishing and enforcing firmer penalties for climbers who fail to comply with existing human waste disposal regulations and by requiring climbers to use personal stool-hauling devices at the higher elevations. Finally, park rangers and health care providers should report clusters of gastrointestinal and other communicable illnesses among climbers to regional public health authorities.

\section{Acknowledgments}

We thank Roger Robinson, Lead Mountaineering Ranger at the Denali National Park and Preserve, for reporting the outbreak and assisting with investigation logistics; 
the clinical staff at the Sunshine Clinic, Talkeetna, AK, for assisting with patient care; and Dr Marvin Bailey, Alaska Section of Epidemiology, for editorial contributions.

\section{References}

1. Dean AG, Arner TG, Sangam S, et al. Epi Info 2000, A Database and Statistics Program for Public Health Professionals for use on Windows 95, 98, NT, and 2000 Computers. Atlanta, Ga: Centers for Disease Control and Prevention; 2000.

2. Murdoch DR. Symptoms of infection and altitude illness among hikers in the Mount Everest region of Nepal. Aviat Space Environ Med. 1995;66:148-151.

3. Rupwate RU, Chitaley M, Kamat SR. Cardiopulmonary functional changes in acute acclimatisation to high altitude in mountaineers. Eur J Epidemiol. 1990;6:266-272.

4. Parry H, Howard AJ, Galpin OP, Hassan SP. The prophylaxis of travellers' diarrhoea; a double blind placebo controlled trial of ciprofloxacin during a Himalayan expedition. J Infect. 1994;28:337-338.

5. Duane TD. Altitude, diarrhea, and retinal hemorrhages. JAMA. 1978;240:214.

6. Hackett PH, Rennie ID, Levine HD. The incidence, importance, and prophylaxis of acute mountain sickness. Lancet. 1976;2:1149.

7. Roach RC, Bartsch P, Hackett PH, Oelz O. The Lake Louise AMS Scoring Consensus Committee. The Lake Louise acute mountain sickness scoring system. In: Sutton JR, Houston CS, Coates G, eds. Hypoxia and Molecular Medicine. New York, NY: Lippincott; 1993:272-274.
8. Singh I, Khanna PK, Srivastava MC, Lal M, Roy SB, Subramanyam CS. Acute mountain sickness. $N$ Engl J Med. 1969;280:175-184.

9. Danzl DF, Pozos RS, Murray PH. Accidental hypothermia. In: Wilderness Medicine Management of Wilderness and Environmental Emergencies. 3rd ed. St Louis, Mo: Mosby; 1995:51-103.

10. Bailey DM, Davies B, Castell LM, et al. Symptoms of infection and acute mountain sickness; associated metabolic sequelae and problems in differential diagnosis. High Alt Med Biol. 2003;4:319-331.

11. Bristow G, Smith R, Lee J, Auty A, Tweed WA. Resuscitation from cardiopulmonary arrest during accidental hypothermia due to exhaustion and exposure. Can Med Assoc J. 1977; 117:247-249.

12. National Park Service. Clean mountain cans. Available at: http://www.nps.gov/dena/home/mountaineering/cmc.htm. Accessed July 6, 2004.

13. National Geographic News. Everest clinic tends ills on high. Available at: http://news.nationalgeographic.com/ news/2003/04/0404_030404_everestdoctor.html. Accessed July 6, 2004.

14. Nepal Mountaineering Association. Trekking peaks climbing rules. Available at: http://www.trekking-in-nepal. com/peaks_climbing/climbing_rules.htm. Accessed July 6, 2004.

15. National Park Service. Climbing Mount Rainier. Available at: http://www.nps.gov/mora/publications/climb.pdf. Accessed on July 6, 2004.

16. Boyce JM, Pittet D. Guideline for hand hygiene in healthcare settings: recommendations of the Healthcare Infection Control Practices Advisory Committee. MMWR Recomm Rep. 2002;51:1-45. 